\title{
Primary Intramedullary Ewing's Sarcoma: A Case Report and Review of the Literature
}

\author{
Oumar Coulibaly1,2, Rachid Gana1, Youssouf Sogoba1,2, Asmaa Regragui ${ }^{3}$, \\ Rachid Maaqili', Fouad Bellakhdar ${ }^{1}$ \\ ${ }^{1}$ Department of Neurosurgery, Hôpital Ibn Sina, Rabat, Morocco \\ ${ }^{2}$ Department of Neurosurgery, Hôpital du Mali, Bamako, Mali \\ ${ }^{3}$ Center of Neuropathology, Rabat, Morocco \\ Email: coulibalynch1@gmail.com
}

Received 3 March 2015; accepted 18 March 2015; published 23 March 2015

Copyright (C) 2015 by authors and Scientific Research Publishing Inc.

This work is licensed under the Creative Commons Attribution International License (CC BY). http://creativecommons.org/licenses/by/4.0/

(c) (i) Open Access

\begin{abstract}
Ewing's sarcoma, a group of primary neuroectodermal tumor (PNET), is an uncommon rare highly malignant tumor mostly affecting the bones of male patients, and accounts for approximately $10 \%$ of the primary malignant bone tumors, and occupies the second place after osteosarcoma in children's less than 20 years. Primary intramedullary Ewing's sarcoma is an extremely rare condition. Here, we present a case of a 16-year-old girl with progressive weakness of lower extremities, inability to walk, progressive low back pain, bilateral leg pain, paresthesia and urinary retention. Spinal MRI showed intramedullary abnormal signal focus from T11 to L3 vertebrae with moderate heterogeneous enhancement on T1 weighted sequences. After surgery, histological examination found a lot of small round-cell tumors with a high nuclear-cytoplasmic ratio, frequent mitoses and apoptotic nuclei suggesting a diagnosis of Ewing's sarcoma and confirmed by CD99 reactivity. She had undergone adjuvant chemotherapy and irradiation and was free of symptoms since 02 years. Within this single pure case of intramedullary Ewing's sarcoma, perhaps the 1st in the English literature, the authors described this extremely rare uncommon localization with a brief review of the literature.
\end{abstract}

\section{Keywords}

Ewing Sarcoma, Primary Intramedullary, PNET, Spinal MRI

\section{Introduction}

Ewing's sarcoma, a group of primary neuroectodermal tumor (PNET) described by Hart and Earle in 1973 [1], 
is an uncommon rare highly malignant bone tumor mostly affecting the extremities with a high predilection for the femur, tibia, pelvis, and humerus and to a considerably lesser extent for the spine, hands, and feet [2]. It accounts for approximately $10 \%$ of the primary malignant bone tumors, occupies the second place after osteosarcoma in children's less than 20 years and affects male patients more frequently than female patients [3]. The disease is most prevalent in white patients and is rare in black patients. In fact, this tumor generally is not thought to involve the central nervous system (CNS) directly but rather, by extension, from the bone or soft tissues [4]. However, from immunohistochemical and ultrastructural studies, the main origin of tumor cell in ES remains unknown [5]. So, primary intramedullary Ewing's sarcoma is an extremely rare condition [6]. With this single case, perhaps the 1st case reported in the literature, the authors described the clinical findings, radiological features and neuropathological data following the outcomes after surgery for this localisation in a 16-year-old girl.

\section{Case Report}

A 16-year-old girl presented to our department with progressive weakness of both lower extremities, inability to walk, progressive low back pain, bilateral leg pain and paresthesia about 1 month and urinary retention for six days durations. Physical examination demonstrated bilateral positive Babinski reflex, flaccid are flexic weakness (motor power 2/5) in both the lower with sensory level at T12 for all the modalities of sensation. Spinal MRI showed intramedullary abnormal signal focus $\left(15 \times 2 \times 2 \mathrm{~cm}^{3}\right)$ at the level of the lower body of T11 to the upper body of L3 vertebrae with moderate heterogeneous enhancement on T1 weighted sequences and no abnormal signal in canalis spinalis from T11 to L3 vertebrae bodies (Figure 1). The patient underwent an urgent posterior decompression to explore this lesion from T12 to L3 vertebrae. During our operation, after durotomy and thoracolumbar midline myelotomy, spinal exploration found a huge intramedullary lesion undistinguished from spinal cord and very hemorrhagic. So, the total resection was not possible without a high risk of spinal cord lesion and despite under microscope manipulation. Histological examination found a lot of small round-cell tumors with a high nuclear-cytoplasmic ratio, frequent mitoses and apoptotic nuclei, with multiple foci of tumor necrosis with blood vessel invasion suggesting a diagnosis of Ewing's sarcoma or lymphoma. Both hematoxylin and eosin $(\mathrm{H}$ and E) and immunohistochemistry staining confirmed the diagnosis of Ewing's sarcoma (Figure 2). The patient recovered very well and was discharged from hospital eight days after surgery. She was referred to the oncologist's center and received 50 grays of chemotherapy and local radiotherapy. For the moment, she is free from symptoms since 02 years.

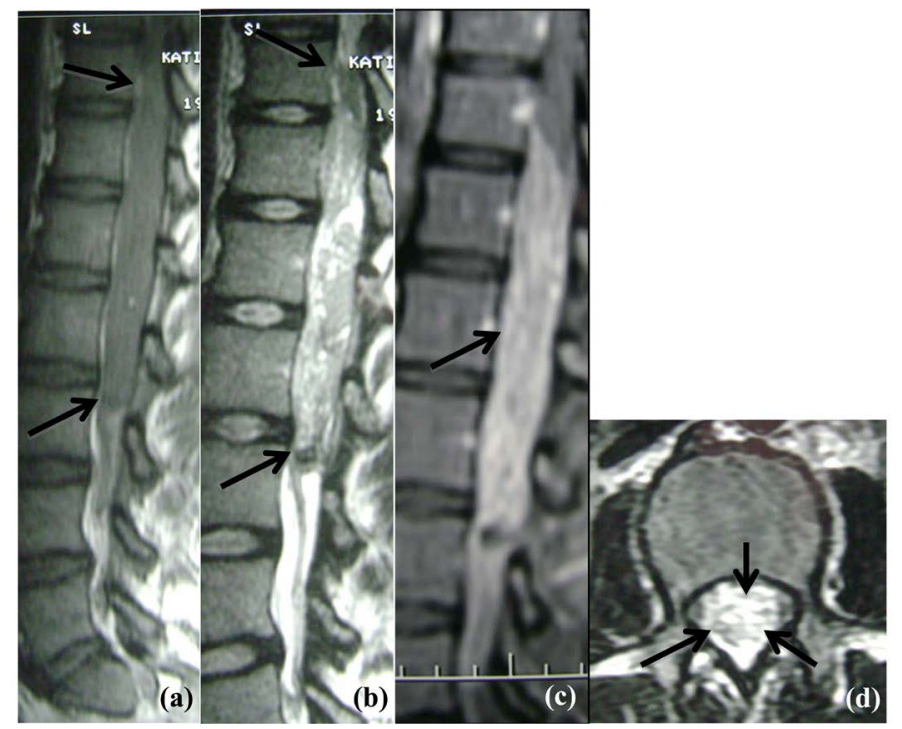

Figure 1. (a) T1-weighted sagittal MRI of the thoracolumbar spine (T11 to L3) reveals a well-defined lesion, hypointense to the spinal cord, located in the substance of the spinal cord (see arrows); (b) T2 weighted sagittal T2 shows a heterogenous hyperintense lesion compared with the spinal cord (see arrows); (c) Gado enhancement scanning showed moderate heterogenous enhancement and no abnormal signal in canalis spinalis from T11 to L3 (see arrow); (d) Axial MRI view shows an heterogenous intramedullary lesion undisdinguish from the spinal cord (see arrows). 


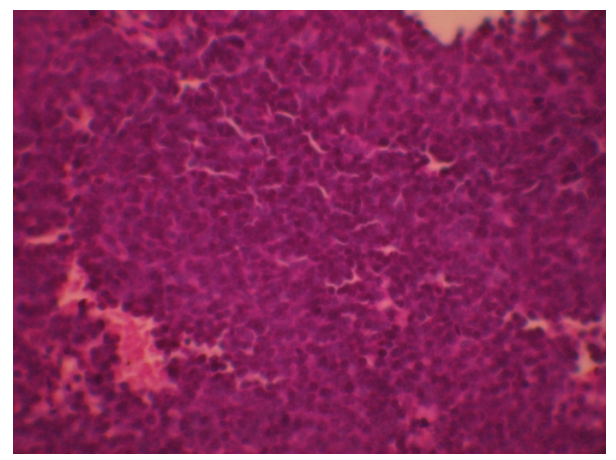

(a)

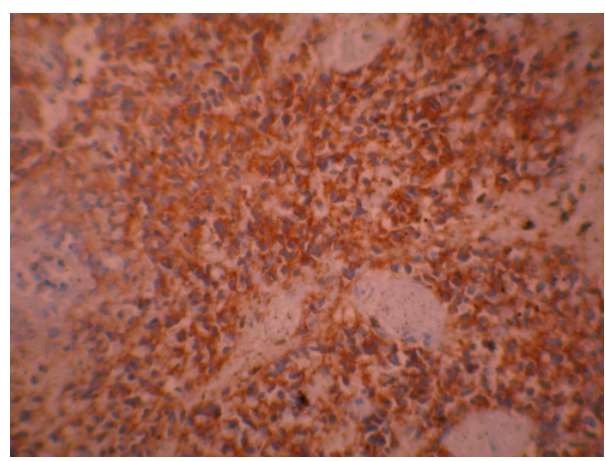

(b)

Figure 2. Photomicrographs of the specimen showing (a) high density of small round cells with a high nuclear-cytoplplasmic ratio (H and E 400); (b) Diffuse positive for CD 99 (400).

\section{Discussion}

Ewing's sarcoma (ES) is a kind of osseous undifferentiated reticulocytic sarcoma, which was firstly reported in 1921 by James Ewing and called at this time diffuse endothelioma of bone [2]. It represents the second most common primary bone malignancy in childhood and adolescence after osteosarcoma, with an estimated annual incidence of 0.6 per million population [6] [7]. It was depicted that the Ewing's sarcoma was originated from immature marrow reticulum tissue, while more and more immunohistochemistry, electron microscope and cytogene studies on sarcoma indicate the tumor originated from neural ectoderm, that is why actually Ewing sarcoma is classified among the PNET [8]-[11]. In this report, the tumor was originated from nerve tissue in the spinal cord and another localization had been seen during our investigation. Extraosseous Ewing sarcoma (EOES) such purely intramedullary ES is a very exceptional uncommon, in our knowledge any case had been reported in the English literature. In reference to EOES, some differential aspects from skeletal Ewing's sarcoma must be notified [12]. The average age of occurrence is around 17 years (range 4 - 47 years), in contrast to 10 years for skeletal Ewing's sarcoma. Both all occurs more commonly in males than females with a ratio of 2/1. [13] Initial symptoms of intramedullary Ewing's sarcoma were completely similar to common tumor in the spinal cord, which usually included back pain and/or radicular pain, decreasing sensation or absence first and followed by motor dysfunction and difficulty of urination and defecation [6] [12]. Most of the patients present with insidious onset neurological deficits. However, intramedullary Ewing's sarcoma had an acute onset and a short course of disease, and a progressive aggravation of nerve damage which caused the complete flaccid paralysis [6]. Thoracolumbar spine is most commonly affected and cervical involvement is rare. On MRI, these lesions commonly appear isointense to muscle on T1weighted images, hyperintense on T2 weighted images and show moderate enhancement on contrast-enhanced T1 weighted images without bony involvement [14] [15]. These data had been found in our case. Neither clinical and MRI examination prior the exploration, none can sure eliminated any relationship between this tumor and the bones. Per operatively, the bones were solids and intacts. Our patient underwent few cycles of chemotherapy and radiation therapy after urgent spinal decompression.

\section{Conclusion}

Primary pure intramedullary Ewing's sarcoma to our knowledge had never been reported in the English literature. An urgent exploration completed by chemotherapy and/or radiation therapy must be the treatment of choice to improve the assumption of responsibilities of these patients.

\section{Acknowledgements}

We would like to thank Mrs. Barry Najah for her supports for this manuscript.

\section{References}

[1] Cai, C.-Q., Zhang, Q.-J., Shen, C.-H., et al. (2008) Primary Intraspinal Primitive Neuroectodermal Tumors: A Case Report and Review of the Literature. Journal of Pediatric Neurosciences, 3, 154-156. 
[2] Henry, J. (2000) Mankin Ewing Sarcoma. Current Opinion in Orthopaedics, 11, 479-485.

[3] Mehta, Y. and Hendrickson, F.R. (1974) CNS Involvement in Ewing's Sarcoma. Cancer, 33, 859-862. http://dx.doi.org/10.1002/1097-0142(197403)33:3<859::AID-CNCR2820330335>3.0.CO;2-O

[4] Weil, R.J., Zhuang, Z., Pack, S., Kumar, S., et al. (2001) Intramedullary Ewing Sarcoma of the Spinal Cord: Consequences of Molecular Diagnostics Case Report. Journal of Neurosurgery, 95, 270-275.

[5] Ambros, I., Ambros, P., Strehl, S., et al. (1991) MIC2 Is a Specific Marker for Ewing's Sarcoma and Peripheral Primitive Neuroectodermal Tumors. Evidence for a Common Histogenesis of Ewing's Sarcoma and Peripheral Primitive Neuroectodermal Tumors from MIC2 Expression and Specific Chromosome Aberration. Cancer, 67, 1886-1893. http://dx.doi.org/10.1002/1097-0142(19910401)67:7<1886::AID-CNCR2820670712>3.0.CO;2-U

[6] Jia, L., Li, G.P., You, C., He, M. and Ye, F. (2009) Intramedullary Ewing's Sarcoma of the Spinal Cord Associated with Hydrocephalus. Neurology India, 57, 828-829.

[7] Güzel, A., Tatli, M., Er, U., Yilmaz, F. and Bavbek, M. (2008) Multifocal Ewing's Sarcoma of the Brain, Calvarium, Leptomeninges, Spine and Other Bones in a Child. Journal of Clinical Neuroscience, 15, 813-817. http://dx.doi.org/10.1016/j.jocn.2006.09.009

[8] Dorfman, H. and Czerniak, B. (1997) Bone Tumors. CV Mosby, St. Louis, 607-663. A Clearly Written and Well-Illustrated Description of the Pathology and Biology of Ewing's Sarcoma and Primitive Neuroectodermal Tumor.

[9] de Alava, E. and Gerald, W.L. (2000) Molecular Biology of the Ewing's Sarcoma/Primitive Neuroectodermal Tumor Family. Journal of Clinical Oncology, 8, 204-211.

[10] Kara, G. (2004) Spinal Cord Ewing's Sarcoma Metastasis: Presentation of One Case. Annals of Nuclear Medicine, 18, 623-626. http://dx.doi.org/10.1007/BF02984585

[11] Behdad, A. and Perry, A. (2010) Central Nervous System Primitive Neuroectodermal Tumors: A Clinicopathologic and Genetic Study of 33 Cases. Brain Pathology, 20, 441-450. http://dx.doi.org/10.1111/j.1750-3639.2009.00314.x

[12] Goel, D., Singhal, A., Gupta, C., et al. (2007) Acute Presentation of Epidural Ewing's Sarcoma. Journal of Pediatric Neurosciences, 2, 18-19.

[13] Shin, J.H., Loo, H.K., et al. (2001) Spinal Epidural Extra Skeletal Ewing Sarcoma: MR Findings in Two Cases. American Journal of Neuroradiology, 22, 795-798.

[14] Kadri, P.A., Mello, P.M., Olivera, J.G. and Braga, F.M. (2002) Primary Lumbar Epidural Ewing's Sarcoma: Case Report. Arquivos de Neuro-Psiquiatria, 60, 145-149. http://dx.doi.org/10.1590/S0004-282X2002000100027

[15] Song, X., Choi, J., Rao, C., Nallu, S. and Nicastri, A.D. (2008) Primary Ewing Sarcoma of Lumbar Spine with Massive Intraspinal Extension. Pediatric Neurology, 38, 58-60. http://dx.doi.org/10.1016/j.pediatrneurol.2007.09.003 